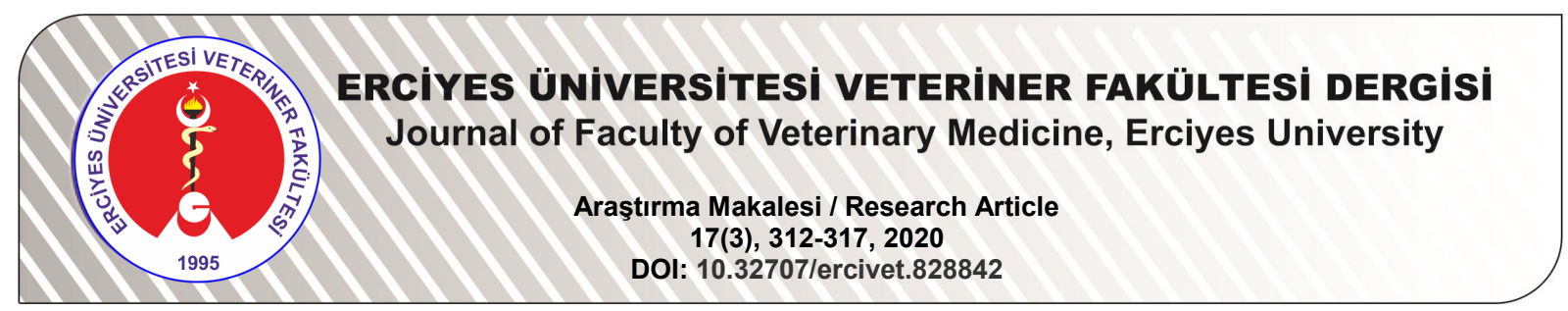

\title{
Jersey Irkı İneklerde Bazı Çevre Faktörleri ve İklim Koşullarının Döl ve Süt Verimi Özellikleri Üzerine Etkisi*
}

\author{
Haşim Umut KOÇ ${ }^{1}$, Mustafa UĞURLU ${ }^{2}$ \\ ${ }^{1}$ Proyem Yem Sanayi Ticaret A.Ş, Samsun-TÜRKIYE \\ ${ }^{2}$ Ondokuz Mayıs Üniversitesi, Veteriner Fakültesi, Zootekni Anabilim Dalı, Samsun-TÜRKIYE
}

\begin{abstract}
Sorumlu yazar: Mustafa UĞURLU; E-posta: mugurlu@omu.edu.tr; ORCID No: 0000-0001-6464-0371
Atıf yapmak için: Koç HU, Uğurlu M. Jersey ırkı ineklerde bazı çevre faktörleri ve iklim koşullarının döl ve süt verimi özellikleri üzerine etkisi. Erciyes Üniv Vet Fak Derg 2020; 17(3): 312-317.
\end{abstract}

Özet: Bu araştırma, Jersey ırkı ineklerin üretim ve üreme özellikleri üzerine bazı çevresel faktörlerin etkisini belirlemek amacıyla yapılmıştır. Araştırmanın veri setini, Amasya Gökhöyük Tarım işletmesinde yetiştirilen Jersey ırkı ineklerin 2014-2016 yılları arasındaki döl verimi, laktasyon kayıtları ve Meteoroloji Genel Müdürlüğü'nden temin edilen iklim verileri kullanılarak hesaplanan sıcaklık-nem indeksi (SNi) değerleri oluşturmuştur. İncelenen çevre faktörlerinden buzağılama yaşı; 2-3, 4-5 ve 6+, buzağılama mevsimi; kış, ilkbahar, yaz ve sonbahar sıcaklık nem indeksi; <70, 70-72 ve $72<$, laktasyon sayısı; 1, 2, 3 ve 4+ olarak gruplandırılmıştır. Araştırmada, buzağılama yaşı ve laktasyon sayısındaki artışın servis periyodunu uzattığı, gebelik başına tohumlama sayıSı (GBTS) ve 305 günlük süt verimini artırdığı tespit edilmiştir. Sıcaklık-nem indeksi ortalamasındaki artışın ise servis periyodunu kısalttığı, GBTS'yi ise artırdığı tespit edilmiştir. 305 günlük süt veriminin sıcaklık-nem indeksi ortalamasındaki mevsimsel artışa bağlı olarak ilkbahar ve yaz aylarında azalma eğiliminde olduğu tespit edilmiştir. Sonuç olarak; Jersey ırkı ineklerde buzağılama yaşı, laktasyon sayısı ve sıcaklık nem indeksi gibi çevresel faktörlerin servis periyodu, GBTS ve buzağılama aralığı üzerine etkisi istatistiksel olarak önemsiz iken, laktasyon sayısı ve buzağılama mevsiminin 305 günlük süt verimi üzerine etkisi istatistiksel olarak önemli $(P<0.001)$ bulunmuştur.

Anahtar kelimeler: Döl verimi, Jersey, sıcaklık nem indeksi, süt verimi

Effect of Some Environmental and Climatic Conditions on Reproduction and Milk Yield Traits in Jersey Cows Summary: This research was performed in order to determine effects of some environmental factors on productive and reproductive traits in the Jersey cows. Data set of this research consisted of lactation and reproduction records of Jersey cows raised at Amasya Gökhöyük State Farm between 2014 and 2016 and climatic data, used to calculated temperature humidity index, obtained from General Directorate of Meteorology. Environmental factors were divided to be calving age; $2-3,4-5$ and $6+$, calving season; winter, spring, summer and fall, $\mathrm{THI} ;<70,70-72$ and $72<$, lactation number; 1, 2, 3, 4+. In this study it was determined that the increase in calving age and lactation number prolonged the days open, as well as increasing the number of insemination per pregnancy and 305 days milk yield. Increasing temperature humidity index shortened days open but it increased the number of insemination per pregnancy. The 305 days milk yield tend to decrease in spring and summer depending on seasonal increase in temperature humidity index. In conclusion, In Jersey, the effect of environmental factors such as calving age, lactation number and temperature humidity index on days open, the number of insemination per pregnancy, and calving interval was insignificant while lactation number and calving season on 305 days milk yield was significant $(P<0.001)$.

Key words: Jersey, milk yield, reproduction, temperature-humidity index

\section{Giriş}

Süt sığırlarının metabolik ve fizyolojik faaliyetleri için en uygun çevre sıcaklığının $5^{\circ} \mathrm{C} / 15^{\circ} \mathrm{C}$, verimlerini azaltmadan yaşam faaliyetlerini devam ettirebildikleri çevre sıcaklığının ise $-5 / 25^{\circ} \mathrm{C}$ arasında değiştiği bildirilmektedir (Akçapınar ve Özbeyaz, 1999). Çevre sıcaklığının $25^{\circ} \mathrm{C}$ 'nin üzerinde olduğu durumlarda laktasyon dönemindeki süt ineklerinin yaşama payı enerji ihtiyacının \%30 oranında arttığı ve bu nedenle laktasyon süt veriminin (Kadzere ve ark., 2002) ve

\begin{tabular}{ll}
\hline Geliş Tarihi/Submission Date & $: 13.07 .2020$ \\
Kabul Tarihi/Accepted Date & $: 24.08 .2020$
\end{tabular} döl veriminin (Gwazdauskas ve ark., 1981) negatif yönde etkilendiği bildirilmiştir. Ayrıca, havadaki bağıl nem yüzdesindeki artışın çevre sıcaklığının etkisini artırarak çiftlik hayvanlarının üzerinde ısı stresi oluşturduğu ve buna bağlı olarak verimlerin olumsuz etkilendiği belirlenmiştir (Ghavi Hossein Zadeh ve ark. 2013).

Isı stresinin, çevre sıcaklığı ve bağıl nemin ortak etkisiyle oluşan "sıcaklık-nem indeksi (SNi)" değeri ile ölçülebileceği bildirilmektedir (Yaslığlu ve İlhan, 2016). Sıcaklık nem indeksi, ilk kez yaz aylarında insanların çevre şartlarından olumsuz etkilenme sevi- 
yelerini değerlendirmek için "discomfort indeks" olarak geliştirilmiştir (Thom, 1958). Sonraki yıllarda, sığır türü için kullanımı yaygınlaşmıştır (Berry ve ark., 1964). Günümüzde SNí, süt sığırlarında ISı stresini değerlendirmek ve Isı stresinden dolayı oluşan performans kayıplarının ölçümünde yaygın olarak kullanılmaktadır (Freitas ve ark., 2006; Hill ve Wall., 2015; Ravagnolo ve ark., 2000).

Hayvancılık işletmelerinde sürünün sürdürülebilirliğinin sağlanması, sürüde ayıklama ve seleksiyon işlemlerinin etkili şekilde yapılabilmesi için döl veriminin önemli olduğu bilinmektedir (Akçapınar ve Özbeyaz, 1999). Döl veriminin kalıtım derecesi düşük olduğundan çevre şartlarının, özellikle çevre sıcaklığındaki artışın oosit kalitesinin bozulmasına, embriyonik gelişimin etkilenmesine, progesteron üretiminin azalmasına ve embriyo ölümlerinin artmasına neden olduğu bildirilmiştir (Nardone ve ark., 2006).

Yüksek süt verimine sahip inekler metabolik faaliyetler sonucunda vücutlarında fazladan ısı ürettiklerinden çevre sıcaklığı ve bağıl nemdeki artışa duyarıdırlar (Purwanto ve ark, 1990). Dünya'da süt üretiminde yoğun olarak Bos cinsinin bir türü olan Bos taurus'un ırklarından yararlanılmaktadır (Alpan ve Arpacık, 1998). Bos taurus ırkları içerisinde ise Jersey ırkı sığırların ısı stresine karşı adaptasyon kabiliyetinin iyi olduğu bildirilmiştir (Garcia-Peniche ve ark., 2005).

Jersey ırkı sığırlar sütçü sığır ırkı sınıfında bulunur ve anavatanı İngiltere ile Fransa arasındaki kanal adalarından birisi olan Jersey adasıdır. Jerseyler sütçü ırk karakterlerine ve erken gelişme kabiliyetine sahip, ortalama ergin dişi canlı ağırlığı 400 kg civarında olan ufak yapılı bir ırktır. Jerseylerde beden rengi açık kahverenginden siyaha kadar değişir. En yaygın görülen renk geyik rengidir. Burun ve merme siyah olup etrafında beyaz bir halka bulunmaktadır. Jersey ineklerde ortalama süt verimi $3000 \mathrm{~kg}$, süt yağı oranı \% 5 olarak belirlenmiştir. Jersey buzağılarda doğum ağırIığının 20 kg civarında olduğu bildirilmiştir. Türkiye’ye ilk olarak 1958 yılında Amerika'dan Samsun Karaköy Harasına getirilmiştir ve Karadeniz ikliminin hakim olduğu Samsun Karaköy Harasında $\left(41^{\circ} 52^{\prime} \mathrm{K}\right.$, $35^{\circ}$ 99'D) yetiştirilmeye başlanmıştır (Alpan ve Arpacık, 1998).

Samsun Karaköy Harasında yetiştirilen Jersey sığır ırkı üzerinde yapılan araştırmalarda 305 günlük laktasyon süt verimleri $3356 \mathrm{~kg}$ (Şahin, 2009), $3467 \mathrm{~kg}$ (Ünalan ve Çankaya, 2010) ve 3786 kg (Teke ve Akdağ, 2010), laktasyon süresi 301.20 gün (Soydan ve Kuran, 2017) ve 290 gün (Teke ve Akdağ, 2010), olarak bildirilmiştir. Samsun Karaköy Harasında yetiştirilen Jersey sığır ırkı üzerinde yapılan araştırmalarda servis periyodu ve buzağılama aralığı 102.84 ve 366.60 gün (Gürses ve ark., 2014), gebelik süresi ve buzağılama aralığı ise 275.20 ve 369.80 gün (Soydan ve Kuran, 2017) olarak tespit edilmiştir.
Jersey ırkı sığırlar 2014 yılında Amasya Gökhöyük Tarım İşletmesine nakledilmiştir. Amasya Gökhöyük Tarım İşletmesi $\left(40^{\circ} 58^{\prime} \mathrm{K}, 35^{\circ} 65^{\prime} \mathrm{D}\right)$ deniz seviyesinde 400 metre yükseklikte ve Karadeniz iklimi ile karasal ikliminin geçiş bölgesindedir. Jersey ırkı süt sığırlarının Karaköy Tarım İşletmesi şartlarında dölverimi (Gürses ve ark., 2014) ve süt verimi (Teke ve Akdağ, 2012; Soydan ve Kuran, 2017) özeliklerinin belirlendiği araştırmalar olmasına karşın, Amasya Gökhöyük Tarım İşletmesi şartlarındaki döl verimi ve süt verimi özellikleri hakkında bilgi bulunmamaktadır. Bu araştırma Amasya Gökhöyük Tarım İşletmesine nakledilen Jersey ırkı sığırların dölverimi ve süt verimi özelliklerinin belirlenmesi amacıyla yapılmıştır.

\section{Gereç ve Yöntem}

\section{Veri setinin oluşturulması}

Bu araştırmada, 2014-2016 yılları arasında Amasya Gökhöyük Tarım İşletmesinde bulunan 496 baş Jersey ırkı ineğe ait 486 laktasyon ve 407 döl verimi kaydı kullanılmıştır. Meteoroloji Genel Müdürlüğü'nden Amasya-Gökhöyük meteoroloji istasyonunda 2014-2016 yılları arasında ölçülen günlük en yüksek sıcaklık, günlük ortalama sıcaklık ve günlük ortalama bağıl nem değerleri temin edilmiş ve $(\mathrm{SNI})=(0.8 \times$ en yüksek çevre sıcaklığı) + [bağıl nem $\times$ (ortalama çevre sıcaklığı-14.4)] + 46.6 formülü kullanılarak sıcaklık nem indeksi değerleri hesaplanmıştır (Davis ve ark., 2003). Sıcaklık nem indeksi değerleri, SNi-1 (<70), SNi-2 (70-72) ve SNi-3 (72<) olarak sınıflandırılmıştır (NADIS, 2017).

\section{Döl verimi özellikleri}

Servis periyodu; buzağılama tarihi ile bir sonraki buzağıya gebe kaldığı son tohumlama tarihi arasındaki süre, gebelik süresi; buzağılama tarihi ile o buzağıya gebe kaldığı tarih arasındaki süre, buzağılama aralığı; birbirini takip eden iki buzağılama tarihi arasındaki süre olarak hesaplanmıştır. Gebelik başına tohumlama sayısı; buzağılamadan sonra bir sonraki buzağıya gebe kalıncaya kadar yapılan tohumlama sayısı olarak alınmıştır (Alpan ve Arpacık, 1998).

\section{Laktasyon özellikleri}

Süt verim özellikleri Amasya Gökhöyük Tarım İşletmesi sığırcılık ünitesinde bulunan sağım sisteminin bilgisayar verilerinden elde edilmiştir. Standart laktasyon süresi 305 gün kabul edilmiştir. 305 günden fazla süren laktasyon verimleri 305 güne göre çevirme faktörleri kullanılarak düzeltilmiştir. 305 günden kısa süren laktasyonlara, kendiliğinden kuruya çıkan ineklerin verimlerinde değişiklik yapılmamış gerçek süt verimleri 305 günlük süt verimi olarak kabul edilmiştir. Laktasyon süresi; buzağılamadan kuruya çıkana kadar geçen süredir. Laktasyon süresi 150 günün altında olan hayvanların laktasyon süresi ve süt verimleri değerlendirme dışı bırakılmıştır. Kuru dönem, buzağı- 
lama aralığından laktasyon süresi çıkarılarak hesaplanmıştır (Alpan ve Arpacık, 1998).

\section{İstatistiksel analizler}

Servis periyodu, gebelik süresi, buzağılama aralığı, gebelik başına tohumlama sayısı özelliklerinin; buzağılama yaşı, sıcaklık-nem indeksi ve laktasyon sayısı gruplarına göre, 305 günlük düzeltilmiş süt verimi, laktasyon süresi ve kuru dönem özelliklerinin ise buzağılama yaşı, buzağılama mevsimi ve laktasyon sayısı gruplarına göre farklılıklarının analizinde SPSS paket programındaki tek yönlü varyans analizi kullanılmıştır. Gruplar arasındaki farklılığın analizi için Duncan çoklu karşılaştırma testleri yapılmıştır (John, 1971; Anonim, 2015).

\section{Bulgular}

\section{Mevsimler ve ısı nem indeksi değerleri}

Mevsim bakımından; günlük en yüksek çevre sıcaklığı, günlük ortalama çevre sıcaklığı ve SNi'nin kış aylarında en düşük seviyede iken yaz aylarında yükseldiği belirlenmiştir. Günlük ortalama nispi nem değeri ise en düşük yaz aylarında en yüksek kış aylarında görülmüştür (Tablo1).
Servis periyodu, gebelik başına tohumlama sayısı (GBTS) ve buzağılama aralığı

Araştırmada döl verimi özelliklerine ait ortalamalar Tablo 2'de verilmiştir. Buzağılama yaşı ve laktasyon sayısının artması ile birlikte servis periyodu artış göstermiş olmasına karşın istatistiksel olarak önemsiz bulunmuştur. Araştırmada, en yüksek servis periyodu (83.67 gün) 6 yaş ve üzeri ineklerde tespit edilmiştir. Sıcaklık-nem indeksi (SNi) sınıfları bakımından yapılan değerlendirmede ise SNI'nin artması ile birlikte servis periyodunun azaldığı tespit edilmiştir. Buzağılama yaşı, SNi ve laktasyon sayısının artışı ile birlikte GBTS ve buzağılama aralığının artma eğilimi gösterdiği tespit edilmiştir. Çevre faktörlerinin; servis periyodu, GBTS ve buzağılama aralığına etkisi istatistiksel olarak önemsiz bulunmuştur ( $P>0.05)$.

\section{Laktasyon süt verimi}

Araştırmada laktasyon periyodunda ait ortalamalar Tablo 3 'de verilmiştir. Buzağılama yaşı ve laktasyon sayısının artması ile birlikte 305 günlük süt veriminin genel olarak artış eğiliminde olduğu belirlenmiştir. Buzağılama mevsimi bakımından en düşük süt verimi $(4810.70 \mathrm{~kg})$ yaz aylarında, en yüksek süt verimi $(5679.68 \mathrm{~kg})$ ise kış aylarında buzağılayan ineklerden

Tablo 1. 2013-2016 yılları arasındaki mevsimlere göre meteorolojik verilere ait ortalamalar ve standart hataları

\begin{tabular}{ccccc}
$\left(\begin{array}{l}\overline{\mathrm{X}} \pm \mathrm{S} \overline{\mathrm{x}}) \\
\text { Mevsim }\end{array}\right.$ & $\begin{array}{c}\text { Günlük En Yüksek } \\
\text { Sıcaklık }\left({ }^{\circ} \mathbf{C}\right)\end{array}$ & $\begin{array}{c}\text { Günlük Ortalama } \\
\text { Sıcaklık }\left({ }^{\circ} \mathbf{C}\right)\end{array}$ & $\begin{array}{c}\text { Günlük Ortalama } \\
\text { Nispi Nem (\%) }\end{array}$ & SNI \\
\hline KıŞ & $8.24 \pm 0.30$ & $3.19 \pm 0.23$ & $78.53 \pm 0.66$ & $44.08 \pm 0.45$ \\
Ilkbahar & $20.33 \pm 0.34$ & $13.07 \pm 0.27$ & $62.42 \pm 0.68$ & $61.49 \pm 0.44$ \\
Yaz & $30.55 \pm 0.20$ & $23.07 \pm 0.15$ & $55.39 \pm 0.53$ & $75.45 \pm 0.21$ \\
Sonbahar & $21.23 \pm 0.38$ & $13.87 \pm 0.32$ & $63.11 \pm 0.70$ & $62.52 \pm 0.49$ \\
\hline
\end{tabular}

SNi: Sıcaklık nem indeksi, ${ }^{\circ} \mathrm{C}$ : Santigrat derece

Tablo 2. Döl verimi özelliklerine ait ortalamalar ve standart hataları ( $\bar{X} \pm S \bar{x}$ )

\begin{tabular}{ccccccc}
\hline $\begin{array}{c}\text { Inncelenen Çevre } \\
\text { Faktörleri }\end{array}$ & $\mathbf{n}$ & $\begin{array}{c}\text { Servis } \\
\text { Periyodu }\end{array}$ & $\mathbf{n}$ & $\begin{array}{c}\text { Buzağılama } \\
\text { Aralığı }\end{array}$ & $\mathbf{n}$ & GBTS \\
\hline Buzağılama Yaşı & & - & & - & - \\
\hline $2-3$ & 228 & $71.80 \pm 4.43$ & 228 & $356.42 \pm 4.41$ & 228 & $1.40 \pm 0.13$ \\
$4-5$ & 96 & $81.66 \pm 4.38$ & 96 & $366.52 \pm 4.37$ & 96 & $1.79 \pm 0.13$ \\
$6+$ & 83 & $83.67 \pm 3.54$ & 83 & $368.72 \pm 3.53$ & 83 & $1.82 \pm 0.11$ \\
SNi & & - & & - & - \\
\hline$<70$ & 248 & $80.64 \pm 2.83$ & 248 & $365.92 \pm 2.82$ & 248 & $1.54 \pm 0.08$ \\
$70-72$ & 35 & $80.62 \pm 5.47$ & 35 & $365.32 \pm 5.46$ & 35 & $1.78 \pm 0.17$ \\
$72<$ & 124 & $74.27 \pm 5.09$ & 124 & $358.72 \pm 5.07$ & 124 & $1.63 \pm 0.15$ \\
Laktasyon sayısı & & - & & - & - \\
\hline 1 & 129 & $76.19 \pm 3.28$ & 129 & $361.02 \pm 3.27$ & 129 & $1.33 \pm 0.13$ \\
2 & 104 & $77.90 \pm 5.23$ & 104 & $362.62 \pm 5.21$ & 104 & $1.71 \pm 0.16$ \\
3 & 65 & $70.56 \pm 7.61$ & 65 & $355.22 \pm 7.58$ & 65 & $1.58 \pm 0.23$ \\
$4+$ & 109 & $84.42 \pm 4.08$ & 109 & $369.52 \pm 4.07$ & 109 & $1.78 \pm 0.12$ \\
Beklenen ortalama & $\mathbf{4 0 7}$ & $\mathbf{7 8 . 1 6 \pm 2 . 6 6}$ & $\mathbf{4 0 7}$ & $\mathbf{3 6 3 . 0 2 \pm 2 . 6 6}$ & $\mathbf{4 0 7}$ & $\mathbf{1 . 6 4 \pm 0 . 0 8}$ \\
\hline
\end{tabular}

GBTS: Gebelik Başına Düşen Tohumlama Sayısı, SNI: Sıcaklık-Nem İndeksi, -:önemsiz 
Tablo 3. Laktasyon periyoduna ait ortalamalar ve standart hataları ( $\bar{X} \pm S \bar{x}$ )

\begin{tabular}{|c|c|c|c|c|c|c|}
\hline $\begin{array}{c}\text { İncelenen Çevre } \\
\text { Faktörleri }\end{array}$ & $\mathbf{n}$ & $\begin{array}{c}305 \text { Günlük Süt } \\
\text { Verimi }\end{array}$ & $\mathbf{n}$ & $\begin{array}{l}\text { Laktasyon } \\
\text { Süresi }\end{array}$ & $\mathbf{n}$ & $\begin{array}{c}\text { Kuru } \\
\text { Dönem }\end{array}$ \\
\hline Buzağılama Yaşı & & - & & $\star \star$ & & - \\
\hline $2-3$ & 278 & $4755.50 \pm 130.31$ & 286 & $318.52 \pm 6.03^{\mathrm{a}}$ & 278 & $59.16 \pm 1.64$ \\
\hline $4-5$ & 106 & $5448.48 \pm 133.58$ & 105 & $316.82 \pm 7.39^{a}$ & 106 & $63.39 \pm 2.02$ \\
\hline $6+$ & 102 & $5021.05 \pm 194.12$ & 105 & $365.42 \pm 11.08^{b}$ & 102 & $58.49 \pm 3.02$ \\
\hline Buzağılama Mevsimi & & $* * *$ & & ** & & - \\
\hline KıŞ & 70 & $5679.68 \pm 181.14^{b}$ & 72 & $327.92 \pm 10.09^{b}$ & 70 & $59.93 \pm 2.75$ \\
\hline İlkbahar & 111 & $4994.39 \pm 134.26^{a}$ & 112 & $333.72 \pm 7.48^{\mathrm{b}}$ & 111 & $62.34 \pm 2.04$ \\
\hline Yaz & 178 & $4810.70 \pm 152.75^{a}$ & 178 & $325.82 \pm 8.51^{\mathrm{b}}$ & 178 & $56.88 \pm 2.32$ \\
\hline Sonbahar & 127 & $5082.74 \pm 174.98^{a}$ & 134 & $320.72 \pm 9.75^{\mathrm{a}}$ & 127 & $59.49 \pm 2.66$ \\
\hline Laktasyon sayısı & & $* \star *$ & & - & & - \\
\hline 1 & 158 & $4460.75 \pm 71.63^{\mathrm{a}}$ & 161 & $324.22 \pm 3.99$ & 158 & $61.27 \pm 1.09$ \\
\hline 2 & 127 & $5491.82 \pm 171.19^{c}$ & 131 & $320.52 \pm 9.54$ & 127 & $64.60 \pm 2.60$ \\
\hline 3 & 71 & $5118.07 \pm 217.58^{b}$ & 72 & $330.02 \pm 12.12$ & 71 & $57.43 \pm 3.31$ \\
\hline $4+$ & 130 & $5100.41 \pm 112.62^{b}$ & 132 & $331.72 \pm 6.27$ & 130 & $59.88 \pm 1.71$ \\
\hline Beklenen ortalama & 486 & $5126.05 \pm 81.35$ & 496 & $326.72 \pm 4.53$ & 486 & $60.98 \pm 1.23$ \\
\hline
\end{tabular}

a,b,c: Aynı sütundaki farklı harflerle gösterilen ortamalar istatistiksel olarak farklıdır.

${ }^{* * *}: \mathrm{P}<0.001 ;{ }^{* *}: P<0.01 ;-:$ önemsiz

sağlandığı tespit edilmiştir. 305 günlük süt verimi ortalamaları arasında farklılıklar buzağılama yaşı grubunda istatistiksel olarak önemsiz, buzağılama mevsimi ve laktasyon sayısı gruplarında istatistiksel olarak önemli $(P<0.001)$ bulunmuştur.

\section{Tartışma ve Sonuç}

\section{Servis periyodu ve gebelik başına tohumlama sayısı (GBTS)}

Servis periyodunun uzunluğu, süt sığırlarında döl verimi performansının ölçülmesinde sıklıkla kullanılan özelliklerden birisidir. Sürü yönetiminde en uygun servis periyodu süresinin 60-80 gün arasında olması gerektiği bildirilmektedir (Akçapınar ve Özbeyaz, 1999). Bu araştırmada servis periyodu; genel ortalaması 78.16 gün olarak bulunmuştur. Bu değer servis periyodu için kabul edilebilir sınırlar içerisindedir. Bu araştırmada servis periyodu, buzağılama yaşı ve laktasyon sayısının artışına paralel olarak artma eğilimi gösterirken sıcaklık-nem indeksi sınıflarında indeks değeri yükseldikçe servis periyodu azalma eğilimindedir. Bu durumun buzağılama yaşı ve laktasyon sayısındaki artış ile birlikte metabolizmada meydana gelen farklılaşmadan dolayı olabileceği düşünülebilir.

Gebelik başına düşen tohumlama sayısının 1-1.5 arasında iyi, 1.5-2.0 arasında orta ve 2.0'ın üzerinde olduğu durumlarda ise kötü olarak kabul edilmektedir (Alpan ve Arpacık, 1998). Bu araştırmada GBTS genel ortalaması 1.64 olarak bulunmuştur. Bu sebeple GBTS'yi 1-1.5 seviyelerine çekebilmek için bu duruma etki edebilecek faktörlere (östrusların tespiti, ineklerin jinekolojik sağlığı, suni tohumlamayı uygulayan kişinin tecrübesi vb) dikkat edilmesi gerektiği söylene- bilir. Buzağılama yaşı ve laktasyon sayısı artışı ile birlikte gebelik başına düşen tohumlama sayısında da artış olduğu belirlenmiştir. En düşük gebelik başına düşen tohumlama sayısı SNi değerinin 70'in altında olduğu durumlarda 1.54 olarak tespit edilmiştir. Genellikle servis periyodu yüksek ise GBTS de yüksek olmaktadır. Zira, servis periyodu uzadıkça her seksüel siklusta ineğe tohumlama yapılmaktadır. Servis periyodunun uzaması ile GBTS'nin artması arasındaki durum bu şekilde açıklanabilir. Bu araştırmada SNi yükseldikçe servis periyodu azalma eğiliminde olmasına rağmen gebelik başına tohumlama sayısını yükseldiği görülmektedir. Bu durum yüksek SNi değerlerinde fizyolojik bazı durumların etkili olabileceği düşünülebilir. Nitekim, SNi'nin reprodüksiyon ve fertilite üzerine olumsuz etkisinin bulunduğu, yani servis periyodunun uzadığı ve gebelik başına düşen tohumlama sayısının arttığı bildirilmesine rağmen servis periyodu ve gebelik başına düşen tohumlama sayısı ile SNi arasında doğrusal bir ilişki bulunmadığı ve bu ilişkinin hormonal mekanizma ile yakından ilişkili olabileceği bildirilmiştir (Ghavi Hossein Zadeh ve ark., 2013).

\section{Laktasyon süt verimi}

$\mathrm{Bu}$ araştırmada buzağılama yaşının artması ile birlikte 305 günlük süt veriminde artış tespit edilmiştir. Buzağılama yaşı grupları arasındaki farklılıklar önemsiz bulunmuştur. Bununla birlikte bu araştırmada elde edilen 305 günlük süt veriminin buzağılama yaşının artması ile birlikte artma eğiliminde olması bakımından kaynaklar ile uyum içinde olduğu söylenebilir (Gürses ve ark., 2014). Bu araştırmadaki ilkbahar (61.49) ve yaz (75.45) aylarındaki SNi'nin Karaköy Harasında 1995-2005 yılları arasında yapılan bir 
araştırmadaki ilkbahar (57.73) ve yaz (74.67) aylarındaki SNi'den yüksek olduğu görülmektedir. Bununla birlikte, bu araştırmada bulunan 305 günlük ortalama süt verimi $(5126.05 \mathrm{~kg})$ Karaköy Harasında yapılan araştırmalarda bildirilen 305 günlük laktasyon süt verimlerinden, $3356 \mathrm{~kg}$ (Şahin, 2009), $3467 \mathrm{~kg}$ (Ünalan ve Çankaya, 2010) ve 3786 kg (Teke ve Akdağ, 2010), yüksek bulunmuştur. Bu farklılığın işletmelerde uygulanan bakım, besleme ve iklim koşullarından kaynaklandığı düşünülmektedir. Nitekim, Jersey ırkı sığırların ısı stresine daha dayanıklı olduğunu bildiren kaynaklar bulunmaktadır (Bryant ve ark., 2007; Keister ve ark. 2002). Araştırmada laktasyon sayısı arttıkça süt veriminde artış tespit edilmiştir. Bu veri Karaköy Harasından Jersey ırkı ile yapılan araştırmalar ve diğer ırklar ile yapılan araştırmalar ile uyumludur (Gürses ve ark., 2014).

Sonuç olarak, Amasya Gökhöyük Tarım İşletmesinde yetiştirilen Jersey sığırlarda, servis periyodunun kabul edilebilir sınırlar içerisinde olduğu tespit edilmiştir. GBTS, SNi artışı ile artmış olmasına rağmen kabul edilebilir sınırlar içerisindedir. Bu araştırmada elde edilen süt verimi sonuçlarının ise Karaköy Tarım İşletmesindeki süt verimi sonuçlarına göre yüksek olduğu tespit edilmiştir. Karaköy Tarım İşletmesinde yetiştirilen Jersey ırkı sığırların Amasya Gökhöyük Tarım İşletmesine nakledilmesi ve burada yetiştirilmesine devam edilmesinin verimler üzerinde kayıp oluşturmadığı söylenebilir.

\section{Kaynaklar}

Akçapınar H, Özbeyaz C. Hayvan Yetiştiriciliği Temel Bilgileri. İkinci Baskı. Ankara: Kariyer Matbaacılık Ltd Şti, 1999; s:73-87.

Alpan O, Arpacık R. Sığır Yetiştiriciliği. İkinci Baskı. Ankara: Şahin Matbaası, 1998; s: 31-217.

Anonim. SPSS21 Statistical Package in Social Sciences for Windows. Statistical Innovations. Inc., Chicago, USA, 2015.

Berry IL, Shanklin MD, Johnson HD. Dairy shelter design based on milk production decline as affected by temperature and humidity. Trans Am Soc Agric Eng 1964; 7: 329-31.

Bryant JR, Lopez-Villalobos, Pryce JE, Holmes CW, Johnson DL. Quantifying the effect of thermal environment on production traits in three breeds of dairy cattle in New Zealand. NZJ Agric Res 2007; 50(3): 327-38.

Davis MS, Mader T, Holt SM, Parkhurst AM. Strategies to reduce feedlot cattle heat stress: Effect of tympanic temperature. J Anim Sci 2003; 81: 64961.

Freitas M, Misztal I, Bohmanova J, Torres R. Regio- nal differences in heat stres in US Holsteins.Proceedings of The Eight World Congress on Genetics Applied to Livestock Production. August,13- 26, 2006; Belo Horizonte-Brazil.

Garcia-Peniche TB, Cassell BG, Pearson RE, Misztal I. Comparisons of Holstein with Brown Swiss and Jersey cows on the same farm forage at first calving and first calving interval. J Dairy Sci 2005; 88: $790-6$.

Ghavi Hossein Zadeh N, Mohit A, Azad N. Effect of temperature humidity index on productive and reproductive performances of Iranian Holsten cows. Iran J Vet Res 2013; 14(2): 106-12.

Gürses M, Bayraktar M, Şimşek ÜG. Jersey ırkı sığırların süt ve döl verim özellikleri üzerine bazı çevre faktörlerinin etkileri. FÜ Sağlık Bil Vet Derg 2014; 28(3): 137-43.

Gwazdauskas FC, Lineweaver JA, Vinson WE. Rates of conception by artificial insemination of dairy cattle. J Dairy Sci 1981; 64: 358-62.

Hill DL, Wall E. Dairy cattle in a temperate climate: the effects of weather on milk yield and composition depend on management. Animal 2015; 9: 138 -49 .

John PWM Statistical Design and Analysis of Experiments. New York: Macmillian, 1971; p: 5-14.

Kadzere CT, Murphy MR, Silanikove N, Maltz E. Heat stres in lactating dairy cows: a review, Livest Prod Sci 2002; 77: 59-91.

Keister ZO, Moss KD, Zhang HM, Teegerstrom T, Edlşng RA, Collier RJ, Ax RL. Physiologyical responses in thermal stressed Jersey cows subjected to different management strategies. J Dairy Sci 2002; 85: 3217-24.

NADIS (National Animal Disease Information Service). Managing heat stres in dairy cows. http:// www.nadis.org.uk/bulletins/managing-heatstressindairy-cows.aspx; Erişim Tarihi: 03.07.2017.

Nardone A, Ronchi B, Lacetera N, Bernabucci U. Climate effects on reproductive traits in livestock. Vet Res Commun 2006; 30: 75-81.

Purwanto BP, Abo Y, Sakamoto R, Furumoto F, Yamamoto $S$. Diurnal patterns of heat production andHR under thermoneutral conditions in Holstein Friesian cows differing in milk production. J Agric Sci (Camb) 1990; 114: 139-42.

Ravagnolo O, Misztal I, Hoogenboom G. Genetic component of heat stres in dairy cattle, development of heat index function. J Dairy Sci 2000; 83: 2120-5. 
Soydan E, Kuran M. The effect of calving season on productive performance of Jersey cows. Mljekarstvo 2017; 67(4): 297-304.

Şahin A. Tarım İşletmeleri Genel Müdürlüğü’ne bağlı işletmelerde yetiştirilen farklı sığır ırklarının süt ve döl verimi özelliklerine ait genotipik ve fenotipik parametre tahmini, Doktora tezi, Gazi Osman Paşa Üniv Fen Bil Ens, Tokat 2009.

Teke B, Akdağ F. Karaköy Tarım İşletmesinde yetiştirilen Jersey ineklerde bazı çevre faktörleri ve kurudönem uzunluğunun süt verimine etkisi. Lalahan Hay Araş Enst Derg 2010; 50: 65-72.

Teke B, Akdağ F. The effect of heat stress on some reproductive traits in Jersey cows under semihumid conditions in Turkey. Bulgarian $\mathrm{J}$ Agric Sci 2012; 18(4): 506-10.

Thom EC. Cooling degress: day air-conditioning, heating and ventilating. Trans Am Soc Heat 1958; 55: 65-9.

Ünalan A, Çankaya S. Genetic parameters and correlations for lactation milk yields according to lactation numbers in Jersey cows. Kafkas Üniv Vet Fak Derg 2010; 16: 995-1000.

Yaslıoğlu E, İlhan H. Güney Marmara süt sığırı yetiştiriciliğinin Isı stresi yönünden değerlendirilmesi. JOTAF2016; 13: 12-9. 